\title{
Responsive turns in Indonesian informal conversation
}

\author{
M.J. VAN NAERSSEN
}

\begin{abstract}
People have all sorts of expectations about how interlocutors will and should behave linguistically when engaged in a conversation. These conversational norms are usually implicit and are sometimes difficult to master in a language that is new to you. This paper presents a model of different types of responses in informal conversation, illustrated with Indonesian examples. It builds upon the conversation analytic notion of preference; distinguishing preferred - or constructive - responses and dispreferred - or competitive - responses. The model is meant as a tool to cross-linguistically compare response behaviour to gain insight in language specific expectations about interaction in informal conversation.
\end{abstract}

KEYWORDS

Informal conversation, preference, Indonesian, conversational norms.

\section{INTRODUCTION}

The Indonesian language may not be the most morphologically or syntactically complex one, mastering the Indonesian way of conversing is far from an easy task for a native Dutch speaker such as myself. My first introduction to the language was through the Indonesisch leerboek (Textbook Indonesian), written and taught from by Hein Steinhauer (2002). At different points in the first few chapters, attention is drawn to linguistic politeness. A discussion of personal pronouns and forms of address were relatively parallel to what I was used to in Dutch, the patientive prefix $d i$-, however, was a completely different story. My native language has no corresponding strategy to this construction and as such it posed problems for getting a feeling about when to use it. It reflects an idea about language use that I was not at all familiar with.

The difficulties in understanding nuances in a language that you do not

M.J, VAN NAERSSEN holds a Mphil degree in linguistics from Leiden University and is currently working on a dissertation about conversational norms and politeness in Dutch and Indonesian informal conversation. The comparative project aims to describe the conversational norms guiding interaction in either language, hoping to identify and explain potential miscommunication situations. M.J. van Naerssen may be contacted at: m.j.van.naerssen@hum. leidenuniv.nl.

(C) 2015 Faculty of Humanities, University of Indonesia

DOI: 10.17510/wjhi.v16i1.372 
speak fluently and the frustration and misunderstanding that can arise from conflicting expectations about how to behave linguistically is still fascinating to me. What are the expectations language users have when they engage in an informal conversation, what norms do they follow and do they expect their interactional partners to follow? If we can find systematic patterns of preference for these aspects in language use, we can compare those patterns cross-linguistically to explain - and maybe even limit - the above mentioned frustration and misunderstanding. This paper introduces the model that I built to map the preferences of language use. The model is created as a tool to compare Dutch and Indonesian conversational expectations and preferences and will be illustrated here with examples from Indonesian.

\section{NORMS OF CONVERSATION}

People follow certain "rules" in conversation: when (not) to speak, when (not) to take turn, when (not) to change the subject. Their exact structuring differs from one speech community to another, but every (near-)native speaker of a particular language supposedly has some basic standards and assumptions as to what is valued and expected in conversation (for example, Wierzbicka 2003). Within Indonesia, Geertz (1973) reports social harmony to be an important cultural value in Java and Bali. An observation that Wouk (2001: 189) believes to have evolved into a particular conversational style "in which solidarity (whether real or manufactured) is overtly marked by various strategies". An important aspect of this conversational style is creating the appearance of solidarity in language use (Wouk 2001: 190). While Wouk focused on the markers kan and ya as possible strategies to evoke solidarity (1998 and 2001 respectively), the present paper is an attempt to uncover the conversational norms that guide language use at a more general level.

Describing what organizational structures are present in conversations is at the heart of conversation analysis. Since it is concerned with "identifying the transindividual, transcontextual, generic properties, patterns and devices associated with how speakers design their contributions", as Drew (1990: 31) points out. These patterns are normative in character and help speakers achieve mutual understanding and coherence in interaction (Drew 1990: 2931). They are "conventional reference points" that speaker use to interpret and understand one another's behaviour (Bilmes 1988: 162).

The basic unit in conversation is an adjacency pair: two turns that are adjacent to each other. The first pair part consists of the speaker doing some type of act: greeting, questioning, offering, requesting, etcetera. To each first pair part (the initiating turn), there are a number of "type-connected" second pair parts. The interlocutor that is about to perform the second pair part, then, selects a second pair part that is relevant to the type that was projected in the first pair part (Sacks 1987 [1973]: 55-56). For example, if the first speaker extends an invitation, the second pair part may consist of an acceptance or a rejection. These alternatives are, however, by no means equivalent. For most types of first pair parts there are several second pair parts to choose from, one 
of which is the preferred one. ${ }^{1}$

Earlier work on repair structures (Schegloff, Jefferson, and Sacks 1977), responses to accusations (Atkinson and Drew 1979), placement of agreement (Sacks 1987 [1973]), and compliment responses (Pomerantz 1978) revealed that speech participants orient toward a certain type of response in conversation. For example, in an unspecified context - a neutral conversation - the preferred response to a first assessment is to agree with that assessment (Pomerantz 1984: 63). Preference in this sense has nothing to do with personal liking or the participants' psychological states. It is concerned with certain observable regularities in the conversation.

Preferred responses are usually immediately performed, structurally simple, and convey the message clearly and unambiguously. Dispreferred responses, on the other hand, are often prefaced, delayed and weakened (Pomerantz 1984: 65). Levinson (1983: 307) relates this notion of preference to the linguistic concept of markedness: preferred responses are unmarked, simple forms; dispreferred responses are marked by structural complexity. Being able to recognize actions and respond to them in a preferred manner is an important aspect of constituting a smooth, natural conversation. The notion of preference is thus central to understanding how speakers manage their mutual relations and how intersubjective understanding is achieved (Boyle 2000: 584).

Aside from these conventions of structure, people seem to have a liking for a certain way of conversing. Including how close you are physically to the other participants; whether you look them in the eye; it all depends on one's cultural background (for example, Clyne 1994).

\section{RESPONSES}

The norms or conventions guiding this preferred way of taking part in conversation are probably most clearly visible in the way interlocutors react to one another: in the responsive acts. Or better yet, in the combination of the initiating and responsive act. Since the responding participant presents a reaction both to the content and form of the previous utterance. The responsive act can thus reflect the degree to which the first speaker followed the norms of conduct in conversation - at least in the eyes of the conversational partner.

Whenever a particular turn is not accepted (either structurally or content wise) the responding participant can make this known by explicitly or implicitly showing their rejection. Surely, people do not only mark their rejection or dismissal of proposed acts, they also show their support and agreement to what was said (and, thanks to our talent to read our interlocutors and anticipate their reaction, more often so). The way in which people show

1 Preference does not only operate at the level of adjacency pairs, but is found to guide interaction at other levels at well. For example, in the event that someone makes a mistake or says something that is in need of some form of repair, people show to have a preference for self-initiated repair over other-initiated repair and self-repair over repair by others (see Schegloff, Jefferson, and Sacks 1977). 
disagreement or dislike to what was said - or to how something was said provides insight in the conversational norms they expect to be followed.

\section{THE DATA}

Conversational norms can be found in any type of interaction. What I am interested in is how people organize everyday informal conversations. What expectations and preferences they have when talking in a non-institutionalized setting; an interactional situation without predetermined rules or regulations. By recovering the norms speakers are oriented toward in an informal friendly conversation, we can formulate a sort of baseline of conversational normative behaviour while more specific goals of conversation add more specific norms to this basis. To be able to interpret and evaluate responses with the least bit of insecurity about the context and circumstances of speaking, both audio and video are essential.

One source to obtain just that, audio-visual material of naturally occurring speech, is a reality TV show. The reality show that was used in this research is a show called Big Brother. It was developed in the Netherlands and first aired there in 1999. After the first season being a huge national success, the format spread globally and reached the Indonesian television in 2011. The reality show revolves around a small group of people moving into a house together for a set period of time. While residing in the house, their every move is captured on video; Big Brother is watching them. Every one to two weeks one of the housemates is voted off the show and has to go home. The ultimate goal is to be the last one to leave the house. The winner receives a money prize and everlasting fame. The residents come from various parts of Indonesian and speak Indonesian with each other.

\section{THE PROPOSED MODEL}

The basic premise underlying this model is that each time interlocutors are confronted with a statement or proposed act, they have to make a decision to either go along with it, supporting the speaker in his act, or not, opposing the speaker's act or proposing a different one. To do a preferred move or a dispreferred one, respectively. Because the preferred response is supportive of the preceding turn, it helps to further construct the conversation in the direction that the first speaker started. Conversely, dispreferred responses redirect the conversation by introducing an alternative, competitive direction. Although there are infinite ways of structuring a responsive turn, several general strategies speakers can be distinguished based on the conversational data.

In Figure 1, each lower level square represents a particular category of strategies. In the remainder of this paper, the different strategies will be explained and illustrated with an example from the Indonesian data. 


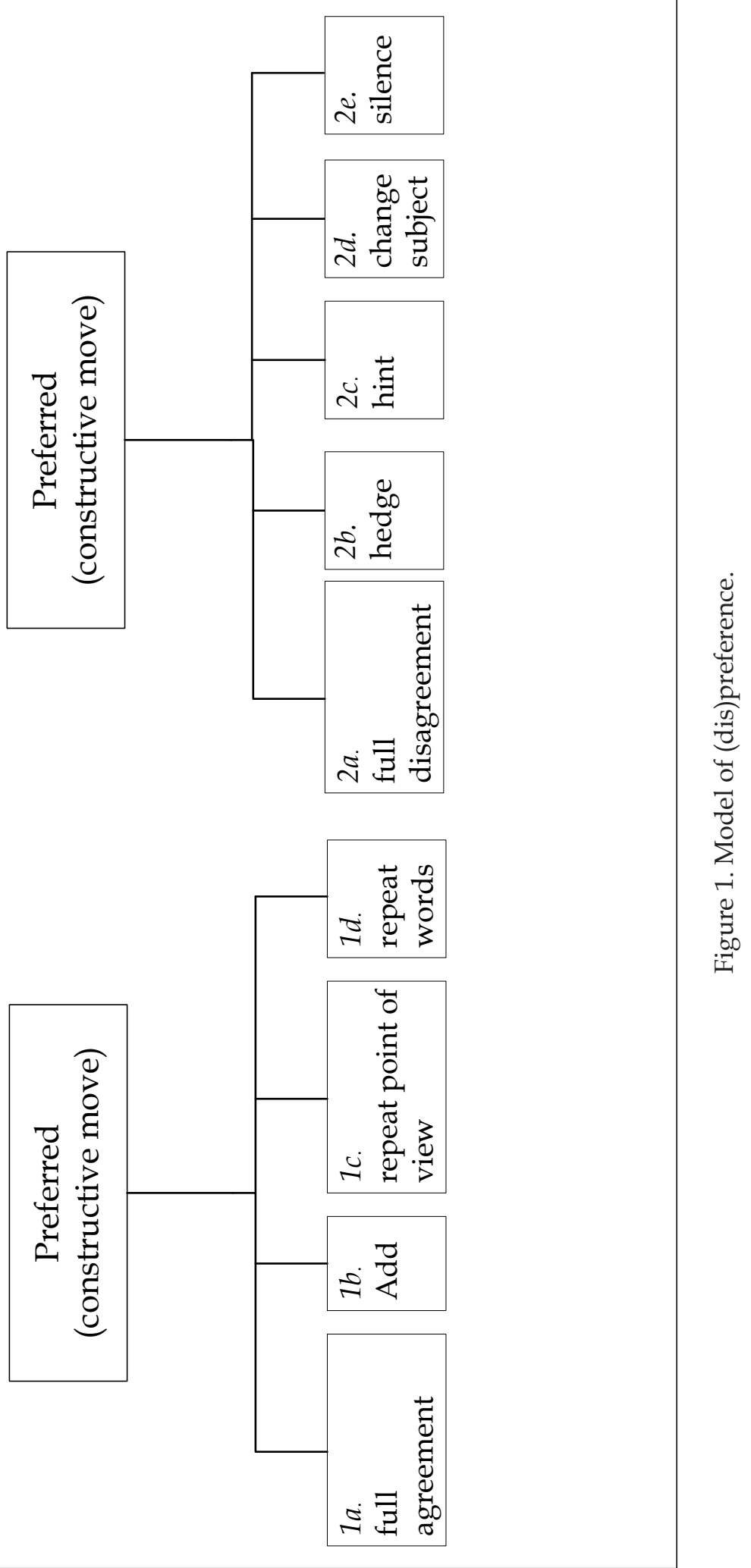




\section{1a. Preferred - full agreement}

These types of responses consist of a single word or a short utterance that expresses support or agreement to what was said in the prior turn. No new information or content is added to the point that was made or the project that was proposed. Simple affirmative markers are often found as in excerpt (1) below. This exchange takes place when one of the housemates, Yeni, is not feeling well. Adam, who is a doctor, has been called to the Diary Room where he was told the produces would like to make sure Yeni is all right by checking her blood. Since he is a doctor, he is asked to draw some of her blood. Upon entering the living room he asks the following question.

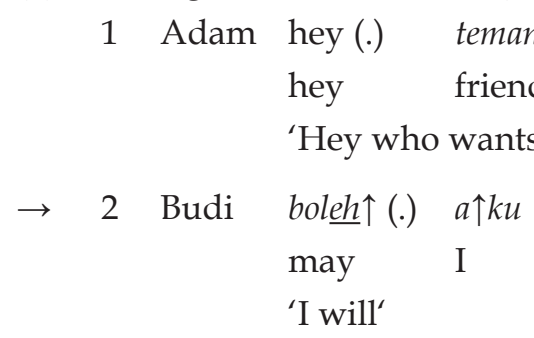

Adam asks a polar question that is formulated to invite an affirmative response. Budi produces a positive response accepting the task of helping Adam. He thus takes up the request. Given that receiving help was what Adam wanted to accomplish by asking this question, Budi produced a preferred response. More elaborate responses such as indeed it is, excellent idea, I completely agree, belong to this category of preferred responses as well, since they too explicitly communicate agreement to what was said, without adding new information to it.

\section{1b. Preferred - add information}

This category consists of responses that both show support and add something extra to what was said in the first pair part. The added information might be presented in the form of an example, an elaboration about one's own experience, a similar situation, and so on. The important thing is that the added information is in support of the act proposed in the previous turn; that it is constructive of the proposed direction of conversation.

This includes those responses in which the second pair part co-constructs the concept or turn that was started in the first pair part, as in fragment (2), in which a small group of housemates is discussing what they need to order for Agung's birthday party.

2 The transcriptions conventions that are used in this paper are explained in an overview following the conclusion. 
(2) BB-IN 4/2

22 Mari gitu begitu apa,

so that what

'like eh, what's it called'

23

yang eh ((stretches arm in front of her face))

that eh

'the one that eh'

24 Yeni oh ya oh ya

oh ya oh ya

'right, right'

25 Mari what's

$\rightarrow \quad 26$ Susan pfieeuw

27

$\rightarrow \quad 28$ Yeni tampak mau ini ((stretches arm)) pfieeuw

appear want this

'that will appear like this'

29 Dina ya yang keluar itu yang le=

ya that go.outside that that

'yes, the one that stretches out'

30

=ya itu.

ya that

'yes, that one'

In line 22 Mari wants to add another item to the list, but cannot seem to find the right word for it. Instead she makes a gesture. Yeni thinks she recognizes what Mari means (line 24) and Susan makes the sound that belongs to the thing they want to put on their shopping list (line 26). In line 28 Yeni says the thing appears and supports her message with both gesture and imitative sound. Dina responds to this co-constructed idea of Yeni, Mari and Susan, by repeating the idea in different words (line 29). She starts by saying 'yes', followed by a description of what the thing does: it stretches out, thus marking her understanding and agreement. Dina's response in line 29 represents an instance of the next category: repeating the presented idea or point of view to show your acceptance or support of it.

\section{1c. Preferred - repeat point of view}

Responses in which the speaker repeats the point of view of statement that was made presented the first pair part, but in their own words, make up this next 
category. By rephrasing the point of view laid out by the previous speaker, the respondent shows they share the feeling or assessment put forward by the other party. In contrast to the previous category, the speaker does not present additional information. Excerpt (3) is taken from a conversation between several housemates following a fight between Adam and Yeni. Yeni is crying and has told her side of the story to some of her housemates. Ali now confronts Adam and says the way he apologized to Yeni does not suffice (lines 26-27). He even reenacts Adam's apology (line 29).

28

29

BB-IN 6/2

26 Ali

$\begin{array}{lll}\text { kamu caranya minta } & \text { maaf= } \\ \text { you way.DEF ask } & \text { apology } \\ \text { 'the way you apologized' } & \end{array}$

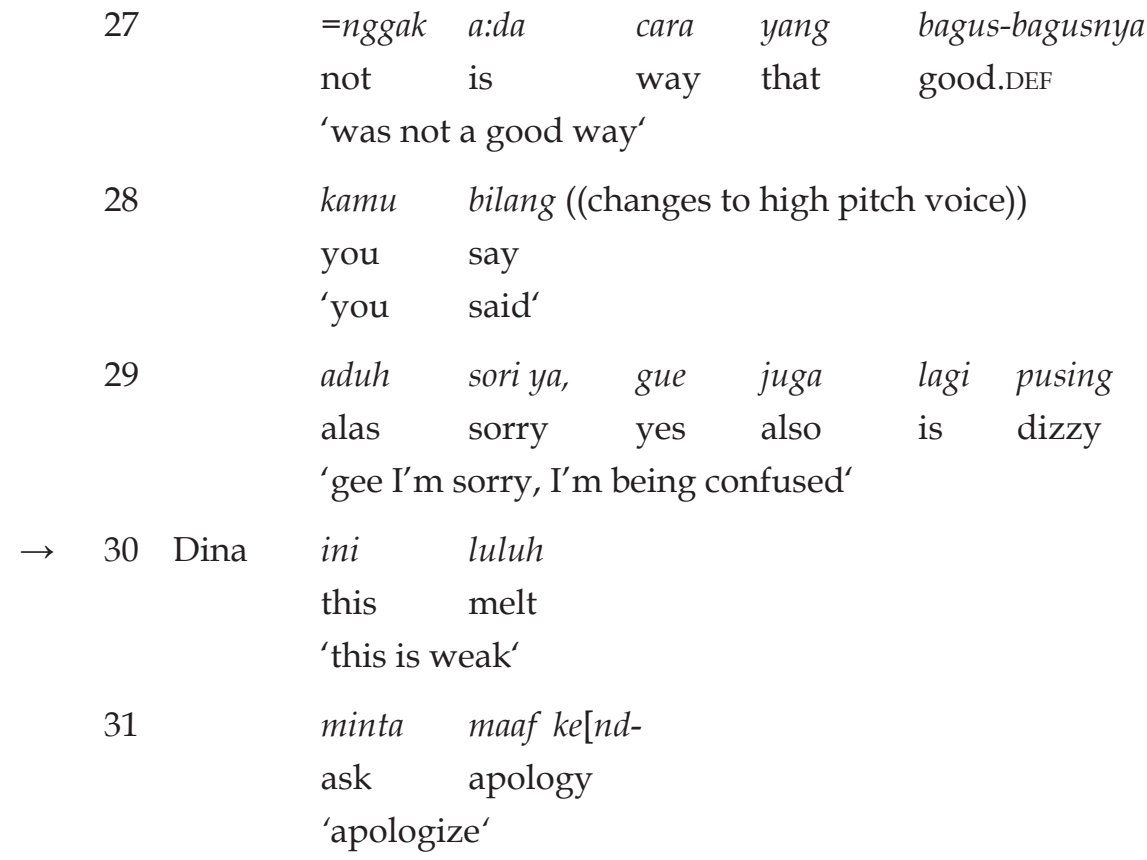

32 Ali

[adam

33 Dina sekeder minta maa::f

just ask apology

'just apologize'

In lines 30-32 Dina repeats Ali's point of view that Adam's apology indeed does not qualify as a real apology and that he should simply say he is genuinely sorry. This type of response is more concerned with contributing to the conversation and adding content than the simple affirmatives. The difference with the previous category - provide additional or complementary information - is that these contributions do not elaborate on the presented act 
or point of view, they do not add new information to the conversation: the point that is made in the second pair part, was already made in the first pair part. It is simply repeated using different words.

\section{1d. Preferred - repeat words}

As opposed to the previous category, where the point of view is enforced by repeating it in other words, this category represents the strategy to directly repeat (part of) the previous or initiating turn. This type of response provides even less new information than the previous two. What is meant by the repetition - what the speaker wants to communicate - is sometimes difficult to pinpoint. Based on reactions to such a repetition from the interlocutor(s), it is clear these responses are interpreted as constructive, supportive moves.

In example (4) a small group of Indonesian housemates is discussing what to put on the grocery list for an upcoming birthday party. After having established they need to buy cake, candles, and matches, Dina (line 16) suggests they could ask for masks. This suggestion is accepted as evidenced by Susan, Dina herself, and Yeni repeating the word for 'mask'.

(4) BB-IN 4/2

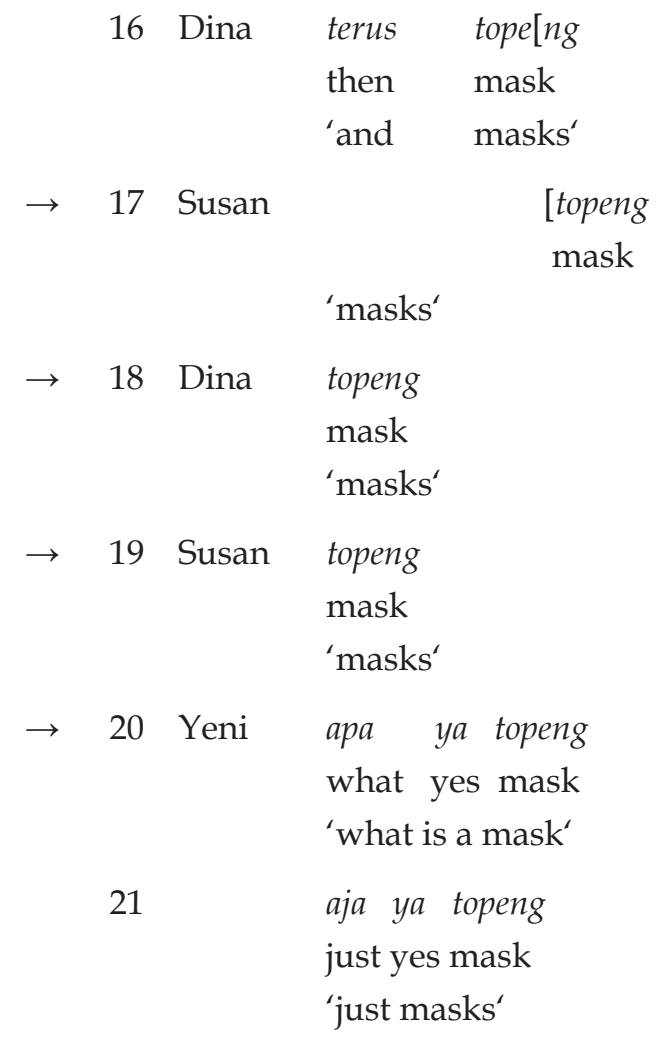

This type of agreement or support is not included within the category of full agreement, but forms a separate category since there is no conventional 
interpretation that 'mask' means 'yes' or that repetition is always or usually affirmative. In repair sequences, for example, repetition can be used to indicate the speaker is not (yet) able to understand or support something that was said in the preceding turn (Jefferson 1972; Schegloff, Jefferson, and Sacks 1977; Dingemanse, Blythe, and Dirksmeyer 2014: 23-24).

The above categories all contribute to the current topic of conversation and are in support of the presented act. They are therefore all preferred responses. While people try to invite preferred responses as much as they can, interlocutors are not always able to produce that constructive or supportive second pair part. Conversational partners can steer the conversation away from the initiated act and topic, by producing a dispreferred second pair part.

\section{2a. Dispreferred - full disagreement}

Some dispreferred responses are made up by a single word or short utterance that literally expresses the speaker does not agree with or support what was proposed by the other party. These types of responses fall under the category of full disagreement, because no new content or information is added. Parallel to the category of responses that convey full agreement, these responses can consist of a single particle (tidak/nggak and bukan in Indonesian) or a more elaborate conventional way to express disagreement.

Example (5) shows a response of this type in line 79. This brief discussion between Dina and Mari takes place immediately after a group discussion about one of their housemates, Paul, being ill and because of that failing to perform one of the tasks assigned to him: to take care of the fish pond in the garden.

BB-IN $12 / 4$

77 Dina

kenapa cowok itu nggak ada i[nisiatifnya

why guy that not is initiative.DEF 'why don't the guys show some initiative'

78 Mari

[tapikan tetep bantu:

but certain help

'but certainly help'

$\rightarrow 79$ Dina enggak, karena mereka udah nggak respek

no, because they already not respect

'no, because they already don't respect him'

Dina wonders why Paul does not show some initiative. Mari suggests he could use some help (line 78), but Dina strongly opposes to that idea in line 79. She replies with a firm 'no' (enggak) and explains that the other housemates have little respect for Paul anymore and will therefore not help him.

It is not just negation particles that can explicitly and unequivocally show disagreement. Statements along the lines of I totally disagree, that is not true, are included in this class as well. As long as the primary function or goal of 
the response is to explicitly convey disagreement to the proposed act, it is considered a full disagreement response.

The following fragment is taken from a discussion between a few of the men on how to execute an assignment the producers of the show gave them. This week's assignment is to lay a new floor in one of the spare rooms. The tiles they have to use are all of a different size, so they have to think hard about what tile fits where. Budi is captain this week and is quite sure of himself when it comes to the floor puzzle. Ali is the first one to suggest two of the parts Paul is carrying are supposed to form the middle (line 43). Paul disagrees and directly states that it is not possible to put that pair of tiles there. Budi believes Ali is right and presses for the others to place the tiles. In line 51 Yanto disagrees with the captain's idea, explicitly stating it is not possible.

BB-IN 5/3

42 Ali

kalau gue bilang tu dua lapis begini
if I say that two layers like.this
'I say the two pieces should be like this'

$\rightarrow \quad 44$ Paul kalau ini

if this

'if you mean this'

pasang di sini nggabisa

put in here not can

'it's not possible to put them here'

46 Budi ini dimasukin aja

this PAT.enter just

'just put these in'

47

dimasukin aja

PAT.enter just

'just put them in'

nggak ada masalah ini

not is problem this

'there is no problem'

49

ali gini-begini

so like.this

'just like this'

50 Budi gini

like.this

'like this' 


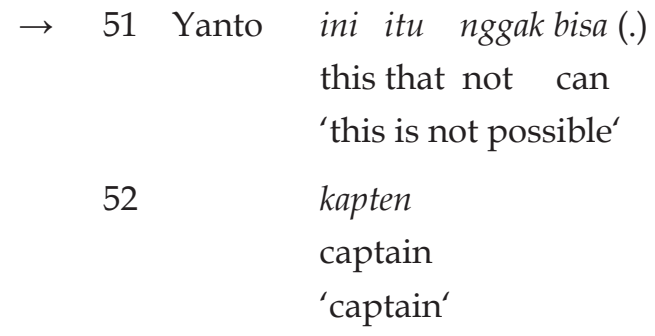

In this example, two parties each stick to their own idea. The tiles go in the middle (Ali and Budi) or they do not (Paul and Yanto). Each of the confronting turns is a competitive move: they try to push the conversation - and hence the placing of the tiles - in one or the other direction. These dispreferred responses (line 44/45, 48 and 51) are all limited in content. The central message is to disagree with or refuse the idea presented in the turn preceding it.

\section{2b. Dispreferred - hedge}

In contrast to the previous category, the type of responses included here are those that present an alternative point of view from the preceding turn, but in a more toned down manner. The disagreement is often presented as a difference of opinion, as in (7). To put Wayan's turn in context, every week the contestants receive a certain amount of money to order groceries, but due to a failed assignment they have a little less money to spend this week. During a house meeting, Kati has voiced her opinion on their daily meals and emphasized how they will run out of food if they do not ration it. She pauses in between her two contributions and seems to hesitate a little, at which point Wayan offers his opinion marked by aku pribadi 'I think' and lebih baik 'better'.

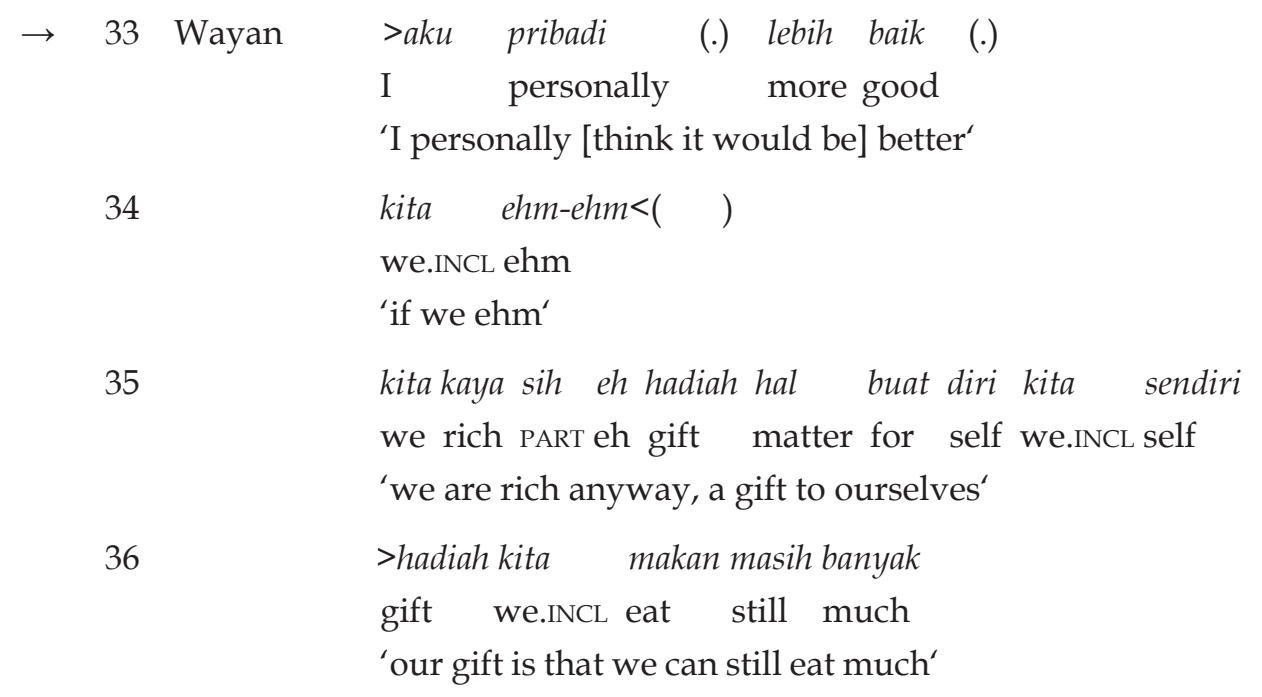


bukan berarti juga hambur ya

not mean also spend ya

'does not mean we can spend it'

38

one bloody juga foya-foya,

one bloody also have.fun

'one [should] bloody [be able to] have fun too'

A little later in the discussion, this week's captain, Budi, presents his view on the case. He, too, states his words to be a personal opinion menurut saya '(literally) according to me'.

BB-IN 3/3

61 Budi jadi (.) menurut saya,
so according.to I
'So, I feel'
saya tetap (.)
I certain
'for sure'
bersekuku dengan porsi yang (.) $\downarrow$ standar.
insist with portion that standard
'we should stick with normal portions.'

The fact that there is disagreement between interlocutors is stated explicitly in these examples, although presented as a suggestion or matter of opinion rather than bluntly rejecting what was said. The next category contains responses that do not convey agreement nor disagreement explicitly. It is up to the interlocutor to infer the intended message.

\section{2c. Dispreferred - hint}

This category of dispreferred responses is marked by the fact that the response is not literally a conditionally relevant reaction to the prior turn. The inferred meaning however does clearly have a function in that same conversation. It is a hint in the right direction one might say. These types of contributions are literally competitive, as they steer away from the ongoing topic or act, but the implied message can be constructive as in (9). In this excerpt Nikki is trying to enter the Big Brother house carrying a big suitcase. There are three doors she can use and she chooses the door on her far left. Unfortunately, that turns out to be not the best of choices as she gets stuck with her suitcase. While trying to push and pull her luggage inside, Tess assures her she will succeed. 




This excerpt contains an example of a helpful hint in line 24. Ali's turn in line 24 opposes Tess' assurance Nikki will manage to get through the door (line 22). He provides an alternative: use the middle door (pintu tengah). He does not openly disagree with Tess stating it is in fact not possible, the strategy he chooses is simply to point out another option. In this same fragment, Susan and Paul produce supportive acts by repeating Ali's idea of directing Nikki to the other door.

While the previous example was constructive at heart - it was a helpful suggestion rather than an attempt to break away from the ongoing topic this strategy can be used to show disagreement as well. In (10) below, an example is given of a hint type response that is of a competitive character. In this excerpt, we see Mari trying to defend Paul. It is his turn to clean the fish pond in the garden, but he does not feel well and went to lie down. When Mari says Paul does not feel well in line 61, Adam interrupts her and states that it is strange having a captain behave this way. He does not criticize Paul directly, but merely voices his feelings about the situation. In line 65 Mari repeats that Paul does not feel well and needs to rest. Adam then asks why he did not tell them (line 65). Again, he does not disagree with what Mari says, but his question does point to the idea that Adam is not too happy with Paul at that moment. 
BB-IN 10/2

54 Mari itu tinggal diisi air aja katanya bang, that leave PAT.fill water just said guy 'he said the only thing left is to fill the water'

55 kalau ada air, isiin. if is water fill.PAS 'as far as the water goes, it just needs to be filled'

56 Adam yang masalah itu bukannyanggakmau satu orang that problem that not not want one person 'the problem is not that it cannot be another person'

57 yang megang lagi(.) that take.care again 'who takes care [of the pond]'

58 takut mati eh afraid dead eh 'I'm afraid [the fish] might die'

59 Mari ya maksudnyakasih tau aja:: yes purpose give know just 'I just wanted to tell you, that's all'

60 Adam ${ }^{\circ} \mathrm{oh}^{\circ}$

61 Mari soalnya diajuga [lagi nggak enak badan problem.DEF he also again not good body 'the problem is he still doesn't feel well'

$\rightarrow \quad 62$ Adam [aneh kok kapten sih begitu strange PART captain PART like 'Strange for a captain to be like that'

63 Mari <enggak> dia lagi nggak enak bada:n no he again not good body 'no he still doesn't feel well'

64 harus istirahat must rest 'he needs to rest'

65 Adam kok nggakbilang sama kami $\uparrow$ PART not tell with us.EXCL 'why didn't he tell us that?' 
The implicit criticizing aspect of these hints makes them dispreferred. The information Mari presented is not received with support, which would be preferred, but is confronted with reluctance and doubt. An even clearer rejection of a proposed act or presented information is to ignore it altogether. By introducing a new and unrelated subject in the response, the speaker can communicate his rejection of the prior turn. This is the strategy described in the next category.

\section{$2 d$. Dispreferred - change subject}

This category includes those responses that are literally irrelevant to the first pair part, similar to the previous category. However, an important aspect of these responses is that can hardly lead to a different interpretation than the speaker not wanting to talk about the proposed topic or not wanting to take part in the proposed action.

The following example is taken from the same episode as extract (10). A little later that day, Paul - who still does not feel well - comes out of the bedroom and walks into the living room. Mari asks him if he has taken some medicine yet in line 109-110 and again in 113. He does not answer her question, but instead responds in line 114 to Dina's question about him being ill (line 112). Mari now insists he should first take some medicine (line 115). After a lengthy pause Paul reacts in line 117, not by (dis)agreeing to her plan but by stating he is going to clean the pond first.

BB-IN 10/2

109 Mari udah $\downarrow$

already

'have you'

110

$\begin{array}{lll}\text { udah minum obat } & \text { belum } \uparrow \\ \text { already drink medicine } & \text { not.yet } \\ \text { 'taken your medicine yet?' } & \end{array}$

111

112 Dina $\quad p a[u l s a k i t \uparrow$

paul ill

'Paul, are you ill?'

113 Mari [udah minum obat belum $\uparrow$

already drink medicine not.yet

'have you taken your medication yet or not?'

114 Paul agak pusingaja

rather dizzy just

'just a headache' 


$\begin{array}{ll}115 \text { Mari } & \begin{array}{l}\text { minum obat dulu dong, } \\ \text { drink medicine first PART } \\ \text { 'just take you medicine first' }\end{array} \\ & (0.5) \\ 116 \quad 117 \text { Paul } & \begin{array}{l}\text { ntar }(.) \text { ngerjain kolam dulu ((walks away)) } \\ \text { later work pond first } \\ \end{array} \\ & \text { 'just a minute, cleaning the pond first' }\end{array}$

Paul's response in line 117 is delayed by half a second, which is an indication that a dispreferred response will follow - and it does. These pauses in itself can, under certain circumstances be interpreted as a communicative act. Those instances are included in the last category of response strategies.

\section{2e. Dispreferred - silence}

Aside from conversational norms regarding when to take turn and who can take the turn, there are conventions about the allowable length of pauses in between turns. Speakers generally try to minimize silence between conversational turns and avoid overlapping talk (Stivers et al. 2009). As discussed above, the delayed production of a turn is one of the markers of a dispreferred response (Pomerantz 1984). But keeping silent can in itself form a turn as well (Kurzon 1998). The absence of a response is the response. Whenever the perceived silence is considered too long, the first speaker may rephrase their point of view in hopes of eliciting a (preferred) response after all.

In contrast to the previous categories, the responses belonging to this category are thus marked by the lack of linguistic material. It is important to note that the silence that is ascribed to the participant that was expected to take turn, is indeed interpreted as such; as a turn carrying communicative intention. Failure to produce a second pair part simply because the first turn was not heard is not considered a meaningful turn. It is a sign to the first speaker the turn may need to be repeated, but there was no intention on the interlocutor's part to communicate anything as they were not aware they were expected to say something in the first place. An example of a meaningful silent turn is presented in (12).

The fragment is again taken from the same episode as (10) and (11). A couple of housemates are discussing who is responsible for the fish pond and start to talk about Paul, who is asleep at that moment. Mari tries to defend him by stating Paul said it should not be that much work to clean the pond, they only need to add fresh water (lines 29-31). Ali reacts in line 31 and emphasizes that Paul was made responsible for the pond so he should take care of it. Mari does not respond to this statement, but instead turns away and ignores Ali, who is staring at her. 


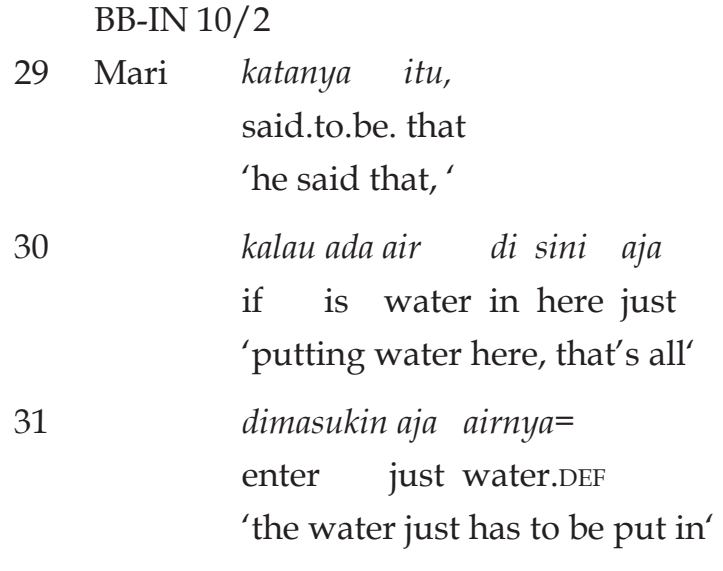

32 Ali =>biar dia yang masukan< $(0.4)$

let 3sG that enter

'let him be the one to enter the water'

33

yang nguras dia.

that drain dia

'the one to clean $i^{\prime}$

34 Mari (0.9)((Mari looks away))

35 Ali kasarnya,

rough.DEF

'it's unfair'

36

masa dia yang berbuat=

if $3 \mathrm{sg}$ that do

'if he doesn't do it'

$\rightarrow \quad 37 \quad=k i t a$ yang tanggung jawab

1PL that responsible

'[why should] we be responsible'

$38 \quad$ kalo mati $\downarrow$

if dead

'if [the fish] die'

$\rightarrow \quad 39$ Mari $\quad(0.7)(($ Mari looks away) $)$

Given that Ali does try to keep Mari engaged in the conversation by trying to clarify his point of view in lines 35-38, he seems to interpret her silence as disagreement with his prior turn. In line 39, Mari again opts for silence which marks the end of the conversation. This last category of dispreferred responses may be the most powerful form of disagreeing, because the interlocutor is left with nothing to react to; there is no real dialogue anymore. At the same time, 
the silent party did not explicitly state they were disagreeing with anything.

\section{CONCLUSION}

Norms about how to structure a conversation are an important part of being able to speak a language. The more organizational norms, such as turn-taking, are reasonably well described. However, norms guiding how to behave linguistically in conversation, when to use what type of construction or how to phrase your contribution is not always easy to understand. What is or is not appropriate or expected in a particular situation is sometimes difficult to assess, especially for non-native speakers.

The model presented in this paper is an attempt to describe different types of responses speakers use. A distinction is made between preferred or constructive moves and dispreferred or competitive moves. Preferred responses are those that support the assessment made or act proposed in the preceding turn and thus help further the construction of the conversation in the direction introduced by the first speaker. Conversely, dispreferred responses are competitive in nature and show disagreement or rejection of the introduced information or act. They - temporarily - steer the conversation in a different direction.

Both preferred and dispreferred responses can be constructed in numerous ways, but it is possible to group them together in several more general types of responses. The following categories of preferred responses are distinguished in the model: showing full agreement with the projected act or idea (1a), adding information to the preceding turn (1b), rephrasing the presented point of view (1c) and repeating words that were used in the preceding turn (1d). What these four types of responses share is that they all support the act they respond to. They help progress the conversation in the direction the previous speaker introduced. Dispreferred responses were categorized according to type as well. Five different types of dispreferred responses are distinguished: expressing full disagreement with or rejection of the presented idea or act (2a), presenting the disagreement in a weakened or hedged way $(2 b)$, responding with a hint leaving the interpretation to the interlocutor $(2 \mathrm{c})$, changing the subject of the conversation (2d), and keeping silent (2e). These five types of responses are dispreferred in the sense that they all introduce a competitive direction of conversation; they are not in line with the idea or act proposed by the previous speaker.

Modelling response types will allow us to qualitatively and quantitatively analyze how responses are constructed and when they are selected. The goal of this paper was to outline the model and explain the different categories, but the model in itself is meant to be used to cross-linguistically compare conversational norms regarding response behaviour. The first results of a contrastive analysis of Dutch and Indonesian data indicates there is indeed a difference in the distribution of selected response strategies between the two languages. The Dutch speakers, for instance, seem to have a stronger tendency to add information to a prior turn by presenting an example or elaborating 
on their own experience in support of their interlocutor's act.

By analyzing responses in natural informal conversation both qualitatively and quantitatively we can formulate the conversational norms speakers seem to be oriented toward when using a particular language. Contrastive analyses of different languages will provide us with a better understanding of possible (or probable) misunderstandings and communication problems. If we know more about the expectations people have in conversational activities we can use that knowledge to help language learners understand how to use the language they are studying, possible relieving them from some of the frustration that comes with the territory of learning a new language.

\section{TRANSCRIPTION CONVENTIONS}

?

word

wOrd

$::$

$><$

[

$=$

A comma indicates a slight rise in intonation, often but not necessarily indicating the speaker will continue the utterance;

A period indicates a falling or final intonation contour, often but not necessarily indicating the end of an utterance;

A question mark indicates rising intonation, often but not necessarily indicating a question is being asked;

The up arrow indicates a sharp rise in pitch;

The down arrow indicates a sharp fall in pitch;

Underlining is used to indicate stress or emphasis is placed on the underlined part of the word;

Upper case letters indicate that a (part of a) word is uttered especially loud;

Colons are used to indicate lengthening or stretching of the sound just preceding them. The more colons, the longer the stretching;

The combination of more than and less than symbols indicates that the talk represented between them is markedly faster than the surrounding talk;

The combination of less than and more than symbols indicates that the talk represented between them is markedly slower than the surrounding talk;

Left square brackets on two successive lines with utterances by different speakers indicate overlap in onset of speaking;

Equal signs at the end of one line and the beginning of the next line indicate there is no pause between the two utterances;

Numbers in parentheses indicate silence, represented in tenths of a second. The (0.4) means there was 0.4 seconds of silence, either between speakers or within an utterance;

A dot between parentheses indicates a short pause, less than 0.2 of a second;

Empty parentheses indicate something is being said, but what exactly was said could not be heard or identified; 


$\begin{array}{ll}((\ldots)) & \begin{array}{l}\text { Comments presented } \\ \text { transcriber's description } \\ \text { facial expressions, sou } \\ \text { marked in this way; }\end{array} \\ \rightarrow & \begin{array}{l}\text { The horizontal arrow } \\ \text { described phenomenon }\end{array} \\ & \text { ABBREVIATIONS USED } \\ 1 & \text { first person } \\ 2 & \text { second person } \\ 3 & \text { third person } \\ \text { AG } & \text { agentive } \\ \text { BB-IN } & \text { Big Brother Indonesia } \\ \text { DEF } & \text { definite } \\ \text { EXCL } & \text { exclusive } \\ \text { INDEF } & \text { indefinite } \\ \text { PART } & \text { particle } \\ \text { PAS } & \text { passive } \\ \text { PAT } & \text { patientive } \\ \text { PL } & \text { plural } \\ \text { SG } & \text { singular } \\ & \end{array}$

\section{REFERENCES}

Atkinson, J. Maxwell and Paul Drew. 1979. Order in the court; The organization of verbal interaction in judicial settings. Basingstoke: Macmillan.

Bilmes, Jack. 1988. "The concept of preference in conversation analysis", Language in Society 17(2): 161-181.

Boyle, Ronald. 2000. "Whatever happened to preference organization?", Journal of Pragmatics 32: 583-604.

Clyne, Michael. 1994. Inter-cultural communication at work; Cultural values in discourse. Cambridge: Cambridge University Press.

Dingemanse, Mark, Joe Blythe, and Tyko Dirksmeyer. 2014. “Formats for other-initiation of repair across languages; An exercise in pragmatic typology", Studies in Language 38: 1, 5-43.

Drew, Paul. 1990. "Conversation analysis; Who needs it?", Text 10(1/2): 27-35. Geertz, Clifford. 1973. The interpretation of cultures. New York: Basic Books. Jefferson, Gail. 1972. "Side sequences", in: David N. Sudnow (ed.), Studies in social interaction, pp. 294-338. New York: MacMillan/The Free Press.

Levinson, Stephen C. 1983. Pragmatics. Cambridge: Cambridge University Press.

Kurzon, Dennis. 1998. Discourse of silence. Amsterdam: Benjamins.

Pomerantz, Anita. 1978. "Compliment responses; Note on the co-operation of 
multiple constraints", in: Jim N. Schenkein (ed.), Studies in the organization of conversational interaction, pp. 79-112. New York: Academic Press.

Pomerantz, Anita. 1984. "Agreeing and disagreeing with assessments. Some features of preferred/dispreferred turn shapes", in: J. Maxwell Atkinson and John Heritage (eds), Structures of social action; Studies in conversation analysis, pp. 57-101. Cambridge: Cambridge University Press.

Sacks, Harvey. 1987 [1973]. “On the preference for agreement and contiguity in sequences in conversation", in: Graham Button and John R.E. Lee (eds), Talk and social organization, pp. 54-69. Clevedon: Multilingual Matters.

Schegloff, Emanuel A., Gail Jefferson, and Harvey Sacks. 1977. “The preference for self-correction in the organization of repair in conversation", Language 53(2): 361-382.

Steinhauer, Hein. 2002. Leerboek Indonesisch. Second revised edition. Leiden: KITLV Uitgeverij.

Stivers, Tanya, et al. 2009. "Universals and cultural variation in turn-taking in conversation", PNAS 106(26): 10587-10592.

Wierzbicka, Anna. 2003 [1991]. Cross-cultural pragmatics; The semantics of natural language. Berlin: Mouton de Gruyter.

Wouk, Fay. 1998. "Solidarity in Indonesian conversation; The discourse marker kan", Multilingua 17: 381-408.

Wouk, Fay. 2001. “Solidarity in Indonesian conversation; The discourse marker ya", Journal of Pragmatics 33: 171-191. 